\title{
An Optimization Model for Tramp Ship Scheduling considering Time Window and Seaport Operation Delay Factors
}

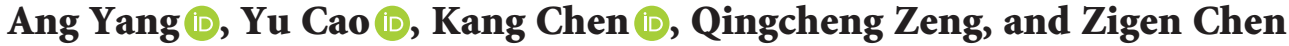 \\ School of Maritime Economics and Management, Dalian Maritime University, Dalian 116026, China \\ Correspondence should be addressed to Kang Chen; chenkang@dlmu.edu.cn
}

Received 14 November 2020; Revised 20 February 2021; Accepted 3 March 2021; Published 23 March 2021

Academic Editor: Yong Wang

Copyright (c) 2021 Ang Yang et al. This is an open access article distributed under the Creative Commons Attribution License, which permits unrestricted use, distribution, and reproduction in any medium, provided the original work is properly cited.

\begin{abstract}
The quantity of electrical coal transported through the tramp shipping network is increasing due to the high demands. This trend has increased the scheduling difficulty combined with the underdevelopment of the private thermal power plant port. The high coal consumption and low port storage capacity requires the scheduling of the tramp ship to be on a strict time window to ensure the continuous operation of the thermal power plant. The low port unloading capacity often leads to the port congestion and delay of the unloading operation. This paper develops a mixed-integer-programming model for the optimization of the tramp ship scheduling to reduce the total operation cost, including the transportation cost and the unloading waiting cost, and the branchand-price algorithm is adopted to solve this large-scale model. The model and algorithm are tested with historical operation data from the thermal power plant in the southern coastal areas of China. The optimized scheme significantly reduces the total operation cost by reducing the unloading waiting time and the number of active vessels in certain periods. The results also demonstrate the algorithm improvement in the aspects of the optimization quality and efficiency comparing with the heuristic solution.
\end{abstract}

\section{Introduction}

The supply of electric coal (coal used to generate electricity) in the southern coastal areas of China follows the basic pattern of transporting coal from north to south [1]. Electric coal is mainly transported through waterways from the main producing regions of northern China to the numerous thermal power plants located in the southern coastal areas [2]. In this vast and complex supply system, large-scale power generation companies (who typically operate approximately 10-20 power plants) play the role of transport organizers. These companies are responsible for not only organizing the electric coal transport fleet through the international ship charter market but also setting the scheduling and operation plan of the fleet. Specifically, these companies make decisions regarding the electric coal transportation plan, ship routing, and scheduling. In the past, the experience and subjective judgment of decision makers (heads of the transportation departments of the power generation companies) have been the primary basis for formulating the electric coal transportation plan [3]. Due to the limited amount of transport and the small size of the fleet, this practice did not present severe flaws at the time and was able to ensure that transportation plans based on the human experience achieved a delicate balance between efficiency and cost.

However, in recent years, the electric coal transportation system has undergone a disruptive change with further increases in the amount of thermal power generation. To meet the growing electricity demand, since 2010, the Chinese government has stepped up efforts to build thermal power units in the southern coastal areas. In turn, the volume of coal and the size of coal transportation fleets have also increased rapidly. In 2010, the company transported only 30,000 tons of electric coal per day and used only five vessels every day on average [4]. In contrast, in 2016, this company transported approximately 70,000 tons per day and used over 20 vessels every day [4].

With the rapid growth of transportation needs, several characteristics of the near-sea electric coal transportation 
have drawn the attention of many researchers. The electric coal transportation is strictly based on pre-made plans, which includes the loading and unloading task, fleet management, and fleet scheduling. Because of the high consumption volume and the low storage capacity of the small thermal power plant port, the transportation tasks have a high requirement on the time sensitivity to ensure the continuous supply of the electrical coal for the thermal plant. The fleets consist of different types and number of ships with different transportation capacities and often supported with the renting of the additional vessel for temporary high capacity demands $[5,6]$. In electric coal transportation systems, the operating capacity of these ports is typically extremely limited because unloading ports are mainly constructed and operated by thermal power plants. These ports can only provide unloading services for one ship at a time, often resulting in long queues of ships waiting to be unloaded (i.e., the port congestion problem). Lastly, the railway has always been one of the essential modes of transportation in the southern Chinese coastal electric coal transportation system [7]. Since the Chinese railway is the dominant transportation mode, the establishment of the modern integrated transportation hubs has also enabled the land-and-water coordinated transport $[8,9]$.

Three factors should be considered for the formulation of the electric coal transportation plan (referred to as the electric coal ship-scheduling problem, ECSSP). The first factor is the time-window constraints of electric coal transportation. Since the storage capacity of the unloading port is quite limited compared to the electric coal consumption, even the minor delay of the transportation could cause the shutdown of the powerplant, which in turn leads to economic and social loss. Thus, it is crucial for the shipment to be completed within their time windows. The second factor is the congestion of the unloading port. The congestion could cause port operation delays, which could not be neglected due to the short voyage duration and high operation frequency [10]. Because of the strict time window and the interdependent scheduling for the whole transportation operation, the delay could have a chain reaction effect, which would decrease the effectiveness of the entire transportation network. The third factor is the synergy between water transportation and railway transportation. The complementarity and cooperation of the railway with waterway transportation are necessary guarantees to ensure the stability of electric coal transportation.

The abovementioned three factors make the current ECSSP highly complex. Decision makers should not only consider the constraint of the shipping time windows on scheduling and the ship unloading processes but also the reasonable cooperative application of water transportation and railway transportation. Thus, it is more complicated than the traditional tramp ship routing and scheduling problem and deserves further study [11]. Therefore, how to design a reasonable electric coal transportation plan has become a significant issue for major power generation companies [3].

Based on the unique characteristics of the electric coal transportation system in the southern coastal areas of China, this paper addresses the ECSSP under the background of hard time-window constraints, unloading port congestion, and synergy between water transportation and railway transportation. The main contributions of this paper are as follows: (1) A new tramp ship routing and scheduling optimization method considering port congestion is proposed. (2) A mixed-integer-programming model is developed to optimize the shipping routing, the corresponding scheduling, and the share rate for water and railway transportation simultaneously (e.g., the beginning time point of the transportation task and the necessary waiting times at unloading ports). (3) A new algorithm based on branch-and-price is designed, which can solve ECSSP efficiently.

This paper is organized as follows. In Section 2, we review the relevant literature, clarify the field of ECSSP research, and analyze the difference and connection between the ECSSP and the corresponding classic problems. In Section 3, a detailed description of ECSSP is provided. A mixed-integer-programming model is developed in Section 4. The algorithm of this model is designed in Section. In Section 6, the model and the algorithm are tested with historical data. The performance of the algorithm is presented, and the practical value of the model and algorithm is discussed based. Conclusions are provided in Section 7.

\section{Literature Review}

According to Ronen's definition, the ECSSP belongs to the tramp ship routing and scheduling problem (TRSP) [12]. Systematic reviews of the literature on the TRSP have been provided by Christiansen et al. [11, 13], Ronen [12, 14], Lane, et al. [15], and Meng, et al. [16]. Christiansen and Fagerholt [17] noted that approximately $40 \%$ of the TRSP models use the set partitioning (SP) model framework, which can characterize the TRSP effectively. The core idea of the SP model framework is to translate the TRSP into a classic set partitioning problem by assuming that all the feasible shipscheduling plans are preknown. A feasible prerequisite for this framework is that decision makers must be able to provide an estimation of the feasible ship-scheduling plans set in advance.

For the TRSP, the early representative studies include the following research. Brown et al. [18] conducted a thorough study of the crude oil transportation problem. In this study, carriers must ship crude oil from the Middle East to Europe and North America with hard time-window constraints. For a known fleet, the decision maker must design a crude oil transport scheduling for each vessel. In response to this problem, Brown et al. [18] constructed an integerprogramming model based on the SP framework. Due to the relatively small size of the problem, the feasible shipscheduling plans set can be obtained by enumeration, which means that the model can be solved efficiently. Therefore, we refer to this kind of method the enumeration SP algorithm (ESPA). Bausch et al. [19] and Perakis and Bremer [20] also used the ESPA to solve the TRSP in their respective studies. Christiansen and Fagerholt [17] discussed an extension of the TRSP where decision makers must consider the impact 
of port nonoperating periods and climatic conditions on the ship-scheduling plan and also built a model based on SP and solved it using the ESPA.

For the port congestion problem, while many studies indicate it is a significant and complex issue, only limited solutions are proposed. Jafari [21] studied the causes of the lag and halt in port operation, including document incompleteness, shortage of ship and truck, the unpreparedness of goods owners, and labor issues. These factors could have significant effects on port operation efficiency. Rahman et al. [22] also study the factors that caused the port operation delay and found that a variety of aspects of ports, ships, cargo owners, and environmental uncertainty all contribute to the port congestion. Their research suggested that the subfactor of foul weather and tide prediction is the most significant factor for port operation delay, which is also the main impact factor for the fleet scheduling problem. For electrical coal transportation, the unloading port for the corresponding thermal power plant is relatively small and only has 1 or 2 berths with low port storage capacity. Once something unexpected happens, subsequent ships can only wait for the available berths for the loading and unloading operations. Thus, the port congestion could cause a significant delay for the following operation. To solve this complex issue, several studies have attempted to provide effective solutions. For example, Kavirathna et al. [23] proposed the vessel transportation policy for the terminals' cooperative management to increase the overall efficiency of the port. The berth scheduling problem is also studied to achieve the minimized total port operation delay $[24,25]$. The problem of port operation delay can also be regarded as the unbalanced distribution of logistic resources in time and space. Some scholars adopted the method of state-space-time (SST) network to promote the collaboration of the logistic network and optimize the distribution of logistic resources in time and space. Wang et al. [26] adopted the state-space-time (SST) network to solve the problem of collaborative two-echelon multicenter vehicle routing optimization. By promoting collaboration among service providers in the logistics network, logistic costs are reduced, transportation efficiency is improved, and transportation emissions are reduced [26]. The green logistics route planning problem with ecopackages could also be optimized by identifying the best location strategy with the state-space-time (SST) network [27]. While those methods show great potential, they are not suitable for the Chinese electric coal transportation issues for the relatively small unloading ports with only limited unloading capacity. Therefore, from the perspective of fleet management, introducing the operation delay time into the TRSP could be an innovative solution for the port congestion issue.

In recent years, scholars have reached a consensus on the modeling of the TRSP [11], and the standard TRSP model has been proposed. However, because the fleet sizes mentioned by these TRSP issues are continuously expanding and the demands for transport are diversified, it has become increasingly difficult to enumerate all feasible ship-scheduling plans. The traditional ESPA-based enumeration method is no longer applicable, and how to solve the TRSP efficiently has become the research focus. According to the standard TRSP model, Brønmo et al. [28] proposed a multistage local search heuristic algorithm and compared the advantages and disadvantages of the new algorithm through four examples. This study proved that the new algorithm could effectively solve the large-scale TRSP within a feasible timeframe. Kobayashi and Kubo [29] proposed a column generation solution algorithm (CGSPA) for the standard TRSP model, in which the shortest path algorithm considering the constraints of time windows were incorporated. Fagerholt et al. [30] studied a variant of the TRSP in which there is a particular mechanism for addressing a shortage in transport capacity. This mechanism allows decision makers to address the shortage of fleet capacity by temporarily renting vessels. However, the chartered vessels must complete at least two transport missions before releasing. For this problem, they proposed an integerprogramming model and a tabu search algorithm (denoted as TSPA) based on the work of Korsvik et al. [31]. Norstad et al. [32] considered the factor of ship speed while studying the TRSP and proposed a local heuristic search algorithm (named multistart) to solve this problem. Hemmati et al. [10] proposed a two-phase hybrid heuristic algorithm for the maritime inventory and routing problem that can also be used to solve the TRSP. Wang et al. [33] also adopted the integerprogramming-model-based approach for searching the reasonable solutions for each vehicle in the distribution center network, which provides the best sequential transportation coalition and efficient model performance. Similar studies include the work of Sopot and Gribkovskaia [34], Gansterer et al. [35], and Cuesta et al. [36].

A comprehensive analysis of the existing relevant literature illustrates that the majority of studies assume that the ships in the fleet do not affect each other during the transportation task. However, in the ECSSP proposed in this paper, the operational statuses of each ship are interrelated. Due to the operation delay caused by port congestion, the deviation of the transportation plan of any ship may have unexpected effects on the transport of other ships. Therefore, the problem proposed in this paper represents a special type of TRSP, in which the scheduling plans of the vehicles (ships) interfere with and affect each other. Solving the ECSSP could enrich the research on the routing and scheduling optimization method with the consideration of the port congestion. The mixed-integer-programming model proposed in this research considered characteristics such as the shipping routing, related scheduling, and land-and-water coordinated transport and achieved simultaneous optimization. This paper also proposed a branchand-price-based algorithm for the effective solving of ECSSP, which would be beneficial to solve other complex models.

\section{Problem Description}

The China Southern Coastal Electric Coal Transportation System (CSTS) studied in this paper is a complex transportation system involving multiple links, multiple constraints, and multiple transportation modes. The system consists of the electric coal supply port (referred to as the loading port), electric coal unloading port (referred to as the 
unloading port), water transport subsystem, and rail transport subsystem. Electric coal must be shipped from the loading port to reach a specific unloading port by the waterway or rail subsystem. The CSTS has five unique features that cannot be ignored.

First, while the spatial distribution of loading ports is concentrated, the spatial distribution of the unloading ports is scattered; thus, the water transport network is star shaped. As shown in Figure 1, in the CSTS, the loading ports are densely distributed in a small area (Supply Port Group) in the western region of the Bohai Sea. These ports typically have sufficient transport capacity with the major coalproducing regions and, thus, have a steady coal supply capacity. In addition, due to the dense distribution of loading ports, the western Bohai Sea region has an extremely high port service capacity and can meet the demand for electric coal loading operations of any volume at almost any time. In contrast, because most of the unloading ports are built near power plants, they are widely clustered in the coastal areas of South China. In terms of the network structure, if we abstractly view the supply port group as a virtual loading port, then the network can be considered as a star-shaped transport network, with the center as the virtual loading port and the peripheral nodes as the unloading ports.

Second, electric coal transportation has strict time and capacity requirements. In practice, due to the limitation of coal storage capacity, thermal power plants must regularly replenish coal inventories and prepare a detailed task list of electric coal purchases and transportation in advance. The task list provides details of each transport mission, including the type of coal to be transported, the volume of coal, the loading port, the unloading port, and the time window for loading and unloading. The time window is the time duration between the earliest possible loading time and the latest possible uploading time of the ship loading and unloading operation according to the berth operation schedule and ship operation schedule. Because the implementation status of the task list directly determines whether the relevant thermal power plants can operate stably, decision makers often demand that the electric coal transportation system strictly fulfills the listed transportation tasks, even without cost considerations. Therefore, the electric coal transport system must be able to provide adequate capacity to ensure that the electric coal is shipped and delivered within the prescribed time window.

Third, electric coal transportation ships have been switched between the status of commissioning and storage. In the CSTS, decision makers usually need to manage a selfowned fleet of 20 to 30 ships of various types. In order to reduce the operating costs of the fleet, decision makers must implement temporary decommissioning of some vessels and choose when to use them again based on the demand for electric coal transportation. Therefore, in ECSSP, decision makers must not only consider the ship's scheduling plan but also must plan the operation status (commissioning and decommissioning) of each ship. Because different types of ships have significantly different decommissioning costs and operating costs, how to formulate an appropriate operation plan based on the needs of electric coal transportation has also become an important issue.

Fourth, the transportation pattern of single demand, single mode, and single voyage is adopted. This transportation pattern is the standard ship-scheduling rules for thermal coal transportation in production and transportation practice with significant advantages. Since 3\%-8\% cargo loss will occur for the transportation mode of the multiple bulk cargo, the adopted transportation could efficiently reduce the cargo loss for the frequent electric coal transportations in the network. Besides, transporting multiple cargoes in a single voyage or transporting the cargoes to multiple unloading nodes could bring significant difficulties for the statistical management of the company. Thus, the transportation pattern of single demand, single mode, and single voyage is adopted in the Coastal Electric Coal Transportation System (CSTS). In the CSTS, this pattern is adopted to facilitate the settlement of freight, avoid mutual pollution between different types of coal, and reduce unnecessary coal losses due to transport. In this pattern, only one mode of transportation can be used for certain transportation tasks. The transportation task cannot be split in any way, and a ship can complete at most one transportation task in a single voyage. This pattern forces decision makers to make a careful choice between water transportation and rail transportation when setting up a fleet to match the ship's capacity with transportation demands. How to make efficient use of the transportation resources of the system has become one of the critical issues that decision makers must solve on the premise of ensuring that transportation tasks are completed on time.

Fifth, the factors involved in transport organization are complex. This feature is mainly reflected in the following two interactive relationships: the interaction between rail transportation and waterway transportation. The interaction relationship selected for this paper is because of the following reasons. Even though the waterway transportation has the advantage of lower transportation batch cost, thermal coal transportation should consider other factors rather than a simple economic factor. The supply of thermal coal must guarantee the continuous operation of thermal power plants as the premise. However, the disruption of the coal transportation could cause the shutdown of the thermal power plant due to the low port storage capacity of the thermal coal port and the high coal consumption rate. As discussed above, the electoral coal transportation by waterway could suffer from the port congestion issue, whereas rail transportation can ignore uncertain factors such as the port congestion. Thus, it is necessary to consider the combination of water transportation and other transportation modes to complete the thermal coal transportation to ensure that thermal coal can be supplied to thermal power plants in time. In the CSTS, the water transportation subsystem is designed, managed, and operated by the power generation group (i.e., the decision maker). Decision makers will form a fleet in advance according to the electricity production plan and then formulate and implement a dispatch plan for electric coal ships based on the transportation 


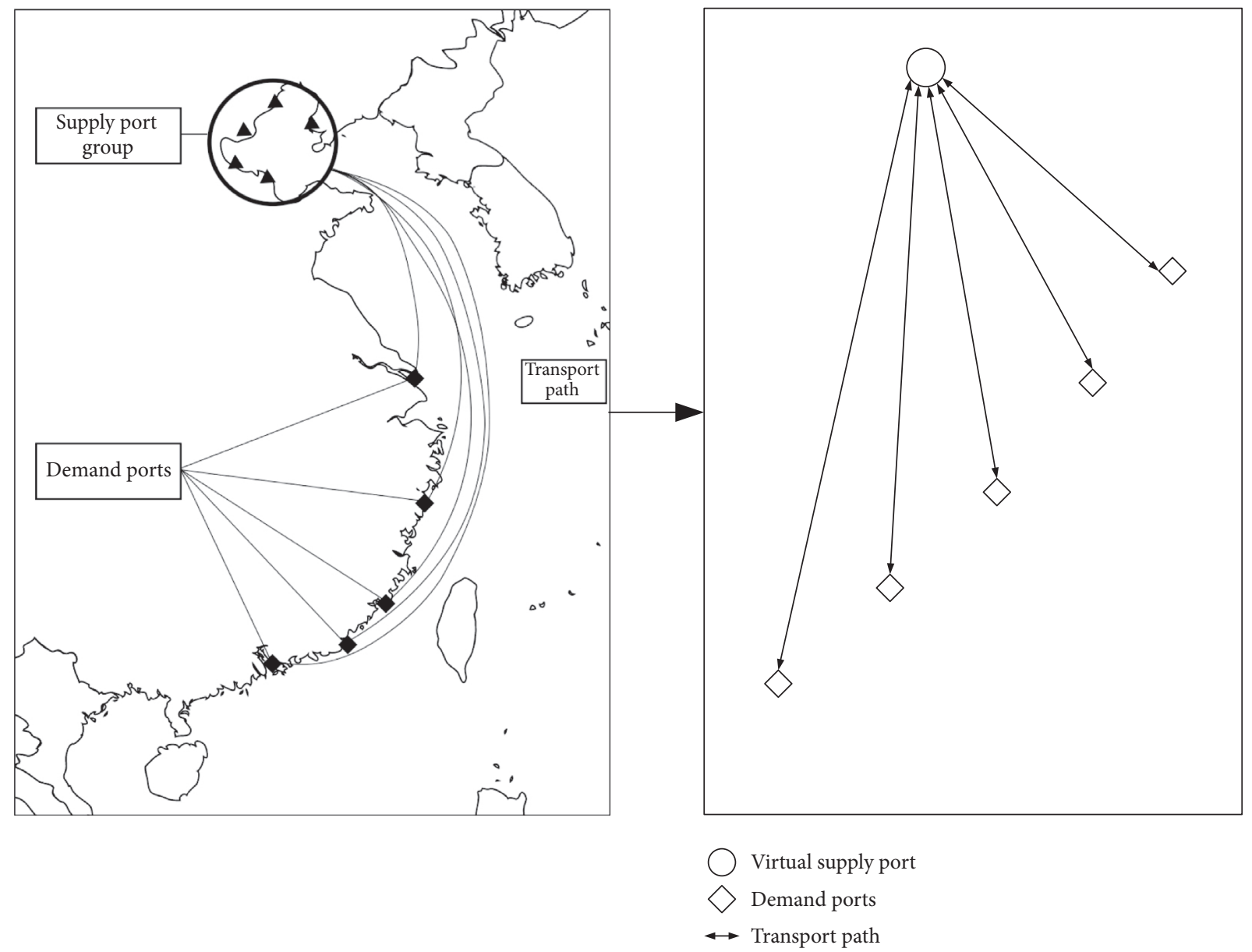

FIGURE 1: Distribution of electric coal loading and unloading ports and topology of the transportation network.

task list and the operational capabilities of each port. The railway transportation subsystem is operated by the government department of railway transportation. The decision makers obtain the necessary transportation services through purchase. The advantages of the waterway transportation subsystem are large transportation capacity and low unit transportation cost; however, the transportation organization is very complicated due to the impact of the port congestion. The advantage of the railway transportation subsystem is that the transportation capacity is abundant, and the transportation process is reliable. The decision maker does not need to consider the transportation scheduling problem, nor is it affected by the factors of port congestion, but the transportation cost is high. Therefore, how to make full use of the complementary advantages of the two transportation modes to improve transportation efficiency and reduce transportation costs is another crucial issue that decision makers must consider.

The interactions between ship-scheduling plans amplify the impact of port congestion. In the traditional TRSP problem, the scheduling process of a single ship is relatively independent, and the operation of each ship does not affect the others. However, in the electric coal ship-scheduling problem, the port congestion has a chain reaction effect on the operation processes of all ships in the plan period, which causes difficulty in the electrical coal supply for the subsequent thermal power plant. For example, when ship A encounters congestion in port $i$, this congestion may delay its arrival at subsequent port $j$, which in turn affects ships B and $\mathrm{C}$ that use port $\mathrm{j}$ as the unloading port. The impact of congestion in a certain port, with the unloading port as a medium, creates a continuous and complex chain reaction causing more significant operation delays throughout the fleet and planning period and ultimately disrupts the scheduling of every ship within the system. Under this mechanism, the improper scheduling of any one vessel may disrupt the operation of the entire system through the amplification of a chain reaction. Therefore, the scheduling problem of ECSSP with the consideration of operation delay is far more complicated than that of the traditional TRSP problem. Decision makers must not only focus on the conventional decision-making problems, such as the matching of ships and transportation tasks and the order of ships to complete transportation tasks, but also accurately consider when each task should begin, when it is completed, and the waiting period at each port, thus reducing unnecessary economic losses.

Based on the abovementioned facts, we present the following description of the ECSSP proposed in this paper. Given are (1) the planning period, (2) the task list of electric 
coal transportation (including transportation volume, loading and unloading port, and loading and unloading time window), and (3) the information regarding renting ships (e.g., daily rent, earliest available time, dead weight, and average speed). Assumptions: there is only one hub-type loading port in the system, and the loading and unloading capacity of the port is sufficient for the transportation needs, and it is the starting point for all of the electric coal transportation tasks; there are several unloading ports in the system, each port has several berths, and berthing and unloading operations are arranged in accordance with the principle of first-come first-serve; electric coal transportation tasks can use either waterway or railway transportation; electric coal transportation adopts the pattern of a single-demand, single-mode, single-batch mode; all ships are activated at the beginning of the planning period, and the decision makers can choose the opportunity to switch (enable or store) according to their needs. However, since this switching requires a long preparation time and complicated procedures, it is assumed that the operating status of each ship can only be switched at most two times during the observation period. Decision making: to achieve the goal of the lowest total cost of the transportation system, the following decisions are required: choosing the transportation method for each transportation task; assigning transportation tasks to each ship; determining the task-execution sequence, the best start and end time; and switching the ship's operating status between active and inactive.

\section{Model Formulation}

4.1. Water Voyage and Land Voyage. To facilitate the reader's understanding, we first introduce the concepts of water voyage and land voyage. Water voyage refers to the procedure by which a ship departs from a loading port, arrives at a designated unloading port, and then returns to the loading port (assuming that the ship must return to the loading port to be on standby after transportation). The water voyage can be further divided into delivery subvoyage and return subvoyage. The former refers to the process of the ship's departure from the loading port to the unloading port, and the latter refers to the process of returning the ship from the unloading port to the loading port. Land voyage refers to the process by which electric coal is transported by the railway system.

Both water voyage and land voyage are derived from the electric coal transportation task. Assume that an electric coal transportation task refers to electric coal being shipped from the port $a$ in period $t_{1}-t_{2}$ and arriving at the port $b$ in period $t_{3}-t_{4}$, where the transportation volume is $d$ tons. Then, the water voyage derived from this task is the process of the loading of $d$ tons of electric coal at the port $a$ in period $t_{1}-t_{2}$, then starting the delivery, arriving at the port $b$ in period $t_{3^{-}}$ $\mathrm{t}_{4}$, and finally, returning to port $a$ after unloading. The land voyage for this task is $d$ tons of coal are loaded from the port $a$ in period $t_{1}-t_{2}$ and arrive at the port $b$ in period $t_{3}-t_{4}$. To simplify the problem, we set the following terms for the land voyage: (1) for any transportation task, the electric coal transportation can always be delivered on time by land voyage and that land voyage is always feasible; however, the cost is higher; (2) because of the single-demand, singlemode, single-voyage mode of transportation, water and land voyages derived from the same transportation are mutually exclusive, and decision makers can choose only one way to fulfill the transportation task. From now on, we shall refer to the water and land voyages derived from the same transportation task as a complementary voyage. For the ease of reading, the sets, parameters, and variables that appear multiple times in this article are listed in Table 1.

It should be noted that this article additionally defines two virtual water voyages, which are, respectively, denoted as 0 and $\tilde{e}$. Voyage 0 means that the ship starts to carry out water transportation tasks from an inactive status, while voyage $\widetilde{e}$ means that the ship no longer performs any water transportation tasks and enters the storage state. For example, if ship A performs voyage 0 at time $t_{1}$ and voyage $\tilde{e}$ at time $t_{2}$, it means that ship A switched from the storage state to the operating state at time $t_{1}$ and from the operating state to the storage state at $t_{2}$. For voyage 0 and voyage $\widetilde{e}$, the values of $t_{i}^{\mathrm{ls}}, t_{i}^{\mathrm{us}}, T_{i}^{l}$, and $T_{i}^{u}$ are all 0 , and the value of $t_{i}^{\mathrm{le}}$ and $t_{i}^{\mathrm{ue}}$ is the length of the observation period.

4.2. Feasible Single-Vessel Scheduling Plan. The concept of a single-vessel scheduling plan can be defined based on the concept of a water voyage. The single-ship-scheduling plan is the work plan and the schedule of the electric coal transportation ship, which determines the operation timing, operation order, and specific water voyage nodes. Let vector $\left(\left(\alpha_{v p}\right),\left(y_{i p}\right),\left(t_{i p}^{s}\right),\left(T_{i p}^{w l}\right),\left(T_{i p}^{w u}\right)\right)$ represent a known singleship-scheduling plan $p$. Whether the design of a single-shipscheduling plan $p$ is reasonable depends mainly on whether the key parameters satisfy the following constraints:

Constraint group 1: the constraints of the task selection and the sequencing of the water voyage.

Equations (1)-(4) provide the first set of constraints that ensure that the single-ship-scheduling plan is feasible, which mainly describes the conditions that a feasible plan $p$ should meet in the selection and sequencing of the water voyage. $x_{i j p}$ is a binary variable; if the ship in the single-ship-scheduling plan $p$ starts water transportation task $j$ immediately after it finishes task $i$, it takes a value of 1 ; otherwise, it is 0 . Equations (1) and (2) ensure that the designs for voyage 0 and voyage $\widetilde{e}$ are satisfied, which means the plan $p$ starts at virtual node 0 and ends at the virtual node $\widetilde{e}$. Equation (3) is used to ensure that any water voyage $i$ has presequence and postsequence voyages if it is to be carried out. The algebraic relationship between $y_{i p}$ and $x_{i j p}$ is defined in equation (4).

$$
\begin{aligned}
& \sum_{j \in I} x_{0 j p}=1, \\
& \sum_{j \in I} x_{\tilde{j e p}}=1, \\
& \sum_{j \in I} x_{i j p}=\sum_{j \in I} x_{j i p}, \quad \forall i \in I,
\end{aligned}
$$


TABle 1: Notation and primary parameters.

\begin{tabular}{|c|c|}
\hline s: & \\
\hline$I$ & $\begin{array}{l}\text { The set of known water voyages, each element of which is denoted as } i \text {; denote } 0 \in I, \widetilde{e} \in I(0 \text { and } \widetilde{e} \text { as virtual nodes, } \\
\text { the meaning will be explained in the following section })\end{array}$ \\
\hline G & The set of unloading ports, each element is denoted as $g$ \\
\hline$V$ & All ships that can be rented, each element is denoted as $v$ \\
\hline$P$ & The set of single-ship-scheduling plan, each element is denoted as $p$ \\
\hline Q & The set of fleet-scheduling plan, each element is denoted as $q, Q \subseteq P$ \\
\hline Para & \\
\hline$t_{i}^{1 \mathrm{~s}}$ & The earliest loading time of the water voyage $i$ \\
\hline$t_{i}^{l e}$ & The latest loading time of the water voyage $i$ \\
\hline$t_{i}^{\mathrm{us}}$ & The earliest unloading time of the water voyage $i$ \\
\hline$t_{i}^{\text {ue }}$ & The latest unloading time of the water voyage $i$ \\
\hline$t_{i p}^{s}$ & The starting time of the single scheduling plan $p$ in the water voyage $i$ \\
\hline$t_{i}$ & Any specific time of the ship during the water voyage $i$ \\
\hline$T_{i p}^{w l}$ & The waiting duration of the loading operation in the single scheduling plan $p$ for the water voyage $i$ \\
\hline$T_{i p}^{i p u}$ & The waiting duration of the unloading operation in the single scheduling plan $p$ for the water voyage $i$ \\
\hline$T_{i}^{r 1}$ & The voyage duration of forward subvoyage in water voyage $i$ (days) \\
\hline$T_{i}^{r 2}$ & The voyage duration of return subvoyage in water voyage $i$ (days) \\
\hline$T_{i}^{l}$ & The net loading time period of the water voyage $i$ (do not include the loading time due to port congestion, days) \\
\hline$T_{i}^{u}$ & The net unloading time period of the water voyage $i$ (do not include the unloading time due to port congestion, days) \\
\hline$w_{v}$ & The transportation capacity of ship $v$ \\
\hline$b_{g}$ & The number of berths in port $g$ \\
\hline$d_{i}$ & The task volume of the water voyage $i$ \\
\hline Deci & \\
\hline$\alpha_{v p}$ & If the single-ship-scheduling scheme $p$ is executed by ship $v$, it is 1 ; otherwis \\
\hline$\beta_{i g}$ & If the port $g$ is an unloading port in waterway voyage $i$, it is 1 ; otherwise, it is 0 \\
\hline$\gamma_{i}$ & $\begin{array}{l}\text { If the task of corresponding electric coal transportation is undertaken by the complementary railway land plan in } \\
\text { waterway voyage } i \text {, it is } 1 \text {; otherwise, it is } 0\end{array}$ \\
\hline$x_{p}$ & If the feasible single-ship-scheduling plan $p \in P$ is selected in the subset $Q$, it is 1 ; otherwise, it is 0 \\
\hline$x_{i j p}$ & $\begin{array}{c}\text { For the single-ship-scheduling plan } p \text {, if the ship starts water transportation task } j \text { immediately after it finishes task } i \text {, } \\
\text { it is } 1 \text {; otherwise, it is } 0\end{array}$ \\
\hline$y_{i p}$ & If the single-ship-scheduling scheme $p$ is executed by water voyage $i$, it is 1 ; otherwise, it is 0 \\
\hline$y_{i p v}$ & If the plan $p$ uses the ship $v$ to perform the water voyage $i$, it is 1 ; otherwise, it is 0 \\
\hline$z_{i p t}$ & $\begin{array}{c}\text { For the corresponding ship of the plan } p \text { at the time point } t \text { (day } t) \text {, if it is currently performing water voyage } i \text { and } \\
\text { in unloading status, it is } 1 \text {; otherwise, it is } 0\end{array}$ \\
\hline
\end{tabular}

$$
y_{i p}=\sum_{j \in I} x_{i j p}, \quad \forall i \in I
$$

Constraint group 2: the constraints on the time point when the water voyage is undertaken.

The relationship between the three variables $t_{i p}^{s}, T_{i p}^{w l}$, and $T_{i p}^{w u}$ and the key time nodes of the water transportation task is shown in Figure 2. For example, in the plan $p$, if the first water voyage executed is $i$, and then, the $t_{i p}^{s}$ is the starting time of the water voyage $i$. Since the execution order of the task is depicted by $x_{i j p}$, the values of $t_{i p}^{s}$ and $x_{i j p}$ are tightly related. In addition, to ensure that the single-ship-scheduling plan is feasible, the values of $t_{i p}^{s}, T_{i p}^{w l}$, and $T_{i p}^{w u}$ should also meet the loading and unloading time-window constraints related to the water transportation task.

$$
\begin{gathered}
t_{j p}^{s} \geq t_{i p}^{s}+T_{i p}^{w l}+T_{i}^{l}+T_{i}^{r 1}+T_{i p}^{w u}+T_{i}^{u}+T_{i}^{r 2}+M\left(1-x_{i j p}\right), \quad \forall i, j \in I, \\
t_{0 p}^{s} \geq \sum_{v \in V} t_{v}^{0} \alpha_{v p}, \\
y_{i p} t_{i}^{\mathrm{ls}} \leq t_{i p}^{s}+T_{i p}^{w l} \leq y_{i p} t_{i}^{\mathrm{le}}, \quad \forall i \in I, \\
y_{i p} t_{i}^{\mathrm{us}}+\left(1-y_{i p}\right)\left(T_{i}^{r 1}+T_{i}^{l}\right) \leq t_{i p}^{s}+T_{i p}^{w l}+T_{i}^{r 1}+T_{i}^{l}+T_{i p}^{w u} \leq y_{i p} t_{i}^{\mathrm{ue}}+\left(1-y_{i p}\right)\left(T_{i}^{r 1}+T_{i}^{l}\right), \quad \forall i \in I, \\
z_{i p t} \leq T_{i p}^{w u}, \quad \forall i \in I,
\end{gathered}
$$






Figure 2: Relationship between the definitions of the water voyage time variables.

$$
\begin{aligned}
t_{i} & \geq t_{i p}^{s}+T_{i p}^{w l}+T_{i}^{r 1}+T_{i}^{l}+T_{i p}^{w u}-M\left(1-z_{i p t}\right), \quad \forall i \in I, \\
t_{i} & \leq t_{i p}^{s}+T_{i p}^{w l}+T_{i}^{r 1}+T_{i}^{l}+T_{i p}^{w u}+T_{i}^{u}+M\left(1-z_{i p t}\right), \quad \forall i \in I, \\
\sum z_{i p t} & \geq y_{i p} T_{i}^{u}, \quad \forall i \in I .
\end{aligned}
$$

Based on the abovementioned analysis, the second set of constraints that ensure the feasibility of the single-shipscheduling plan is shown in equations (5)-(11), where $M$ represents a maximal positive number. The binary variable $z_{i p t}$ represents whether the corresponding ship of the plan $p$ is performing water voyage $i$ and at unloading status at the time point $t$ (dayt); if so, then, $z_{i p t}$ takes a value of 1 ; otherwise, it is 0 . Equations (5) and (6) depict the algebraic relationship between $t_{i p}^{s}$ and $x_{i j p}$ ensuring the start time of a water voyage is the end time of its preceding voyage, where $t_{v}^{0}$ represents the initial time for the ship $v$ to be operational. Equations (7) and (8) ensure that the settings of $T_{i p}^{w l}, T_{i p}^{w u}$, and $t_{i p}^{s}$ satisfy the timewindow constraints of the relevant water voyage. Equation (9) requires that the value of $z_{i p t}$ is 0 ; when $y_{i p}=0$, namely, if the plan $p$ does not implement the water voyage, the ship used in the plan shall not be in the unloading state of the water voyage at any time. Equations (10) and (11) determine the logical relation between $T_{i p}^{w l}$, $T_{i p}^{w u}$, and $z_{i p t}$ at time $t_{i}$. Equation (12) makes sure that the time for ship docked in the port is not less than the port unloading time used in the plan $p$.

Constraint group 3: constraints on ship selection considering the single-vessel scheduling.

Equations (13)-(15) are the third group of constraints, which mainly describe the conditions that the feasible plan $p$ should meet in choosing the vessels. Among them, $w_{v}$ indicates the transportation capacity of the ship $v$; the variable $y_{i p v}$ indicates whether the plan $p$ uses the ship $v$ to perform the water voyage $i$; if it is, it is taken as 1 ; otherwise, it is taken as 0 ; $d_{i}$ represents the task volume of the water voyage $i$. Equation (13) is used to ensure that plan $p$ uses only one vessel. Equation (14) is used to ensure that the capacity of the vessel is larger than the transportation demand. Equation (15) is the mathematical relationship among $y_{i p v}, y_{i p}$, and $\alpha_{v p}$; that is, when $y_{i p}$ and $\alpha_{v p}$ are both equal to $1, y_{i p v}$ is taken as 1 ; otherwise, it is 0 .

It should be noted that, in order to reduce the complexity of solving the model and construct a linear programming optimization model, this article linearizes equation (15) to obtain equation (15a). The apostrophe in the equation label indicates it is the linearization version of the equation without the apostrophe. In the following, we define a plan $p$ that satisfies equation (1)-(15) as a feasible single-ship-scheduling plan. The complete set of such feasible plans is denoted as $P$.

$$
\begin{gathered}
\sum_{v \in V} \alpha_{v p}=1 \\
\sum_{v \in V} w_{v} y_{i p v} \geq d_{i} y_{i p}, \quad \forall i \in I \\
y_{i p v}=y_{i p} \cdot \alpha_{v p}, \quad \forall i \in I, v \in V \\
\frac{1}{2}\left(y_{i p}+\alpha_{v p}\right)-\frac{1}{2} \leq y_{i p v} \leq \frac{1}{2}\left(y_{i p}+\alpha_{v p}\right), \quad \forall i \in I, v \in V
\end{gathered}
$$

\subsection{Feasible Fleet Scheduling Plan}

As mentioned at the end of Sections 1 and 2, there will be an interactive relationship between different singleship feasible plans when they are implemented. The fourth set of constraints will be constructed for the impact between different single-ship feasible solutions.

Constraint group 4: constraints on the interactive relationship between multiple single-ship plans. 
In the present study, we define a subset $Q(Q \subseteq P)$ as the fleet scheduling plan. The elements of the subset $Q$ are a single-ship plan and should satisfy the following two conditions. (1) the single-ship single-task constraint: in $Q$, a ship can only carry out a single-ship-scheduling plan once during the planning period. (2) The exclusivity constraint of port operation: the number of unloading ships should not exceed the number of berths designed in the port at the same time.

Based on the abovementioned analysis, we propose the feasible conditions for the subset $Q$ shown in equations (16) and (17). Among them, the variable $x_{p}$ represents whether the feasible single-ship-scheduling plan $p \in P$ is selected in the subset $Q$; if it is, $x_{p}$ is taken as 1 ; otherwise, $x_{p}$ is 0 . The indicator variable $\beta_{i g}$ indicates whether the port is an unloading port in the waterway voyage $i$. If it is, it is taken as 1 ; otherwise, it is taken as 0 . $b_{g}$ represents the number of berths in the ports $g$. Equation (16) ensures that each ship can only be operated once with a single-ship-scheduling plan, which means parts of the fleets are allowed to not participate in the plan. Equations (16a) and (16b) are the linearization versions of equation (16) for the same constraint. Equation (17) ensures that the number of unloading ships does not exceed the number of berths designed in the port at the same time. Equations (17a) and (17b) are the linearization versions of equation (17) for the same constraint.

$$
\begin{gathered}
\sum_{p \in P} \alpha_{v p} x_{p} \leq 1, \quad \forall v \in V, \\
\frac{1}{2}\left(\alpha_{v p}+x_{p}\right)-\frac{1}{2} \leq u_{v p} \leq \frac{1}{2}\left(\alpha_{v p}+x_{p}\right), \quad \forall v \in V, p \in P, \\
\sum_{p \in P} u_{v p} \leq 1, \quad \forall v \in V, \\
\sum_{i \in I} \sum_{p \in P} \beta_{i g} z_{i p t} x_{p} \leq b_{g}, \quad \forall g \in G, \\
\frac{1}{2}\left(z_{i p t}+x_{p}\right)-\frac{1}{2} \leq m_{i p t} \leq \frac{1}{2}\left(z_{i p t}+x_{p}\right), \quad \forall i \in I, p \in P, \\
\sum_{i \in I} \sum_{p \in P} \beta_{i g} m_{i p t} \leq b_{g}, \quad \forall g \in G .
\end{gathered}
$$

\subsection{Electric Coal Fleet Transportation Plan Optimization Model}

Based on the abovementioned constraints, the scheduling process of waterway transportation has been fully characterized. The last set of constraints is introduced for the constraints of the choice of waterway and rail transportation.

Constraint group 5: constraints on the choice of waterway and rail transportation.

According to the assumptions, any water transportation voyage can be replaced by a complementary railway land voyage, so the decision maker can choose either of them. The fifth set of constraints contains only equation (18). Equations (18a) and (18b) are the linearization versions of equation (18) for the same constraint. It shows that if any feasible single-vessel solution for the waterway voyage $i$ is not selected for set $Q,\left(y_{i p} x_{p}=0\right)$, the task of corresponding electric coal transportation must be undertaken by the complementary railway land plan $\left(\gamma_{i}\right.$ must be 1).

$$
\begin{gathered}
\sum_{p \in P} y_{i p} x_{p}+\gamma_{i} \geq 1, \quad \forall i \in I \\
\sum_{p \in P} q_{i p}+\gamma_{i} \geq 1, \quad \forall i \in I, \\
\frac{1}{2}\left(y_{i p}+x_{p}\right)-\frac{1}{2} \leq q_{i p} \leq \frac{1}{2}\left(y_{i p}+x_{p}\right), \quad \forall i \in I, p \in P .
\end{gathered}
$$

Based on the definitions of constraint $1-5$, we can provide a complete mathematical model (denoted as ECSSM). The model is also improved from the common SPP model. Let $c_{p}^{\text {op }}$ represent the operating costs of the plan $p ; c_{i}^{a}$ represents the cost of the land voyage associated with the water voyage $i ; c_{v}^{r}$ represents the daily rent of ship $v$ (which equals to the difference between the daily operating cost when the ship $v$ is activated and the daily management cost when ship $v$ is sealed). Equation (19) is the objective function of the model to minimize the total system transportation cost, which equals to the sum of the cost of water voyage and railway land. Equation $(20)$ is used to calculate $c_{p}^{\mathrm{op}}$. In 
particular, similar to SPP, in this model, the feasible singleship-scheduling plan $P$ and water voyage $I$ are considered as known, and the decision variables of the model are $x_{p}$ and $\gamma_{i}$. ECSSM:

$$
\min \sum_{p \in P} c_{p}^{\mathrm{op}} x_{p}+\sum_{i \in I} c_{i}^{a} \gamma_{i}
$$

s.t. equation $(1) \sim(18)$.

$$
c_{p}^{\mathrm{op}}=\sum_{v \in V}\left(t_{\frac{s}{e p}}^{s}-t_{0 p}^{s}\right) c_{v}^{r} \alpha_{v p}, \quad \forall p \in P .
$$

The ECSSM is a large-scale linear integerprogramming model. The ECSSM takes into full consideration the synergetic transportation of sea and rail, the time-window constraints of transportation tasks, and the congestion in the port. It can adequately describe the characteristics of the electrical coal transportation in the southern coastal areas of China. However, the ECSSM still have some limitation for the wide application of costal waterway transportations. With the consideration of the electric coal transportation's operational practice in the Chinese coast area, the transportation pattern of single vessel, single mission, and single voyage is adopted for the tramp ship schedule. Although this assumption is suitable for the scope of this study, it also limits the application of the ECSSM for the applications with other characteristics, such as multiple-voyage or multiple types of cargoes. Furthermore, the ECSSM also adopts the assumption of fixed vessel speed, which is a common assumption for the waterway transportation with the consideration of the economical speed. However, since the thermal power plant could not risk the shutdown, the tramp ship would consider changing the vessel speed to deliver the electric coal in time for extreme situations. Therefore, adopting the assumption of fixed speed ignores the other possible measure to mitigate the damage caused by the operation delay. Although the ECSSM has such limitations; these limitations only become significant in the other cases with distinct differences as well as the extreme application cases. For the purpose of studying the electric coal transportation in the Chinese coastal area, the ECSSM could accurately describe the characteristics of transportation and suitable for further study.

The crux of the model's solvability lies in the size of the single-ship-scheduling plan set $P$. However, the plan set $P$ involves the setting and combination of many factors such as waterway voyage selection, waterway voyage sequencing, waterway operation time node, and waiting time. In reality, the size of the plan set $P$ is extremely large, and the enumeration algorithm cannot meet the needs of practical application. Thus, we must design a targeted solution to solve the ECSSM efficiently.

\section{Algorithm Design}

The ECSSM is a large-scale mixed-integer optimization model. At present, there are three methods for solving such models. One is the traditional calculation method based on branch and bound. This method has low efficiency and is powerless for many complicated problems. The second is the heuristic algorithm based on the evolutionary framework. The efficiency of this kind of algorithm is relatively high, but it cannot ensure that the global optimal solution is obtained, and the algorithm has poor robustness and unstable calculation results. The third is the branch-and-price algorithm (B\&P) which has been widely adopted in recent years. Because of the high computational efficiency of the branch-and-price algorithm and the theoretically accurate solution of large-scale models, it has become an ideal tool for solving large-scale mixed-integer optimization. Therefore, this paper adopts the branch-and-price algorithm to solve the abovementioned model.

The core of the branch-and-price algorithm is column generation. The idea of column generation evolved from the original Dantzig-Wolfe decomposition idea. It decomposes the original model into two models, called the master model (MM) and submodel (SM). The decision variables in the main model are only a subset of all variables in the original model. The role of the submodel is to continuously introduce new variables into the main model until the optimal solution of the original model is obtained. The objective function of the submodel is the reduce cost of the introduced variable.

The flow of the branch-and-price algorithm can be briefly described as follows: (1) Construct an initial solution and solve the main model. In theory, any feasible solution satisfying all constraints can be taken as the initial solution. In addition, by solving the main model, the dual price of each constraint in the model is also obtained. (2) Solve the submodel and obtain the reduce cost of the variable to be introduced, that is, the objective function of the submodel. If the reduce cost is negative, the variable (called column in the main model) is added to the main model. (3) Solve the main model and submodel repeatedly until the reduce cost of the submodel is nonnegative. In theory, the optimal solution of the main model at this time is the optimal solution of the original model. The abovementioned process is shown in Figure 3.

\subsection{Main Model and Submodel}

5.1.1. Mathematical Expression of the Main Model. The mathematical expression of the main model (denoted as $\mathrm{MM})$ is shown in equations (21)-(25). Among them, $\widetilde{P}$ represents the currently known feasible set of single-ship plan; the rest of the symbols are the same as before. The structure of this model is similar to that of the ECSSM; the difference is that the MM uses $\widetilde{P}$ to replace the original full set $P$ of feasible solutions of the single-ship plan. Since $\widetilde{P}$ is known, the variables of this model are $x_{p}$ and $\gamma_{i}$. Since $\widetilde{P} \subseteq P$, the optimal solution of the MM should theoretically be the upper bound of the ECSSM. The scale of $\widetilde{P}$ is much smaller than that of $P$, so we use Gurobi to solve the model. 


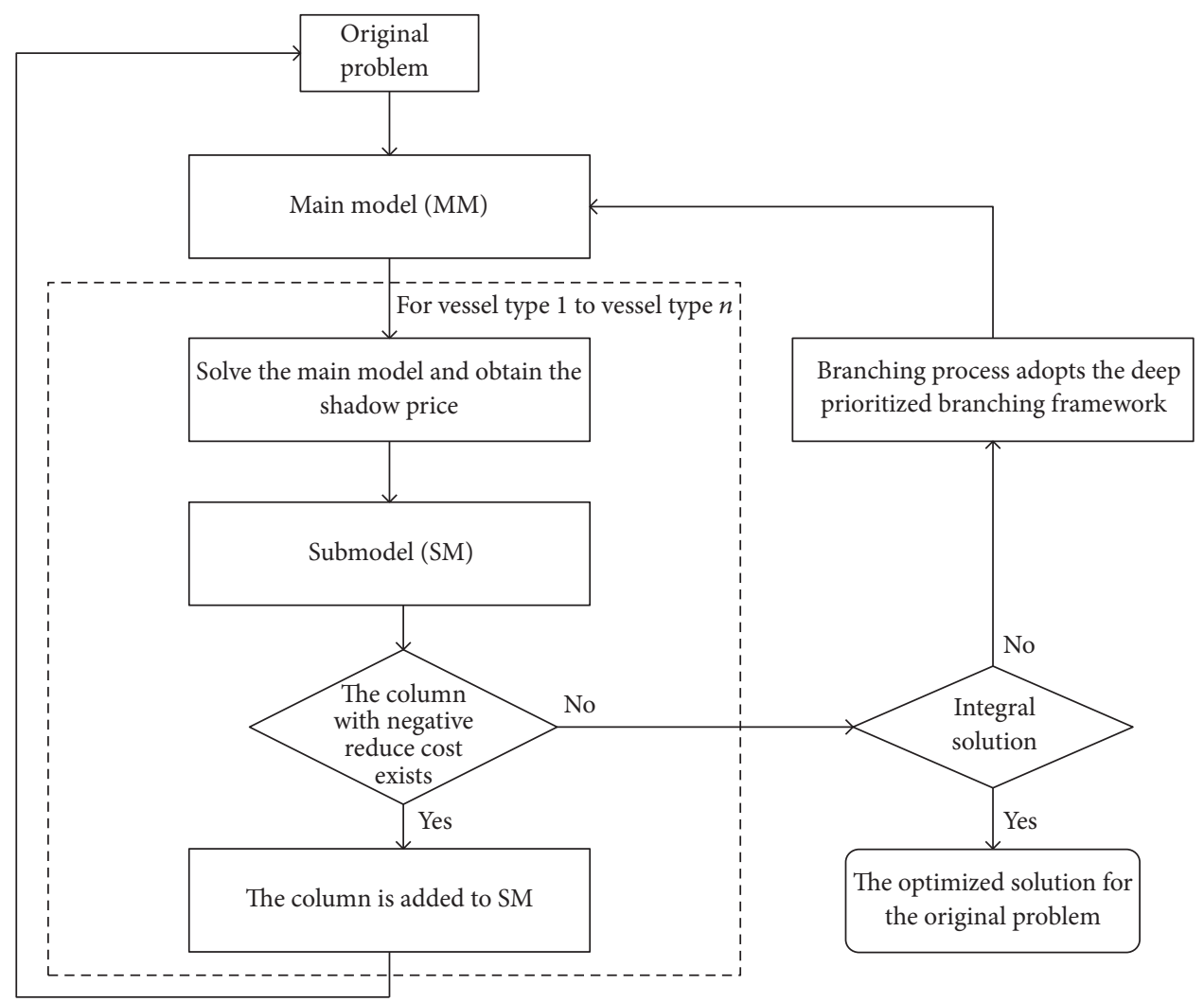

Figure 3: Diagram of branch-and-price algorithm.

ECSSM-MM:

$$
\begin{aligned}
& \min \sum_{p \in \widetilde{P}} c_{p}^{s} x_{p}+\sum_{i \in I} c_{i}^{t} \gamma_{i}, \\
& \text { s.t. } c_{p}^{s}=\sum_{v \in V}\left(t_{\tilde{e} p}^{s}-t_{0 p}^{s}\right) c_{v}^{r} s_{v p}, \quad \forall p \in \widetilde{P}, \\
& \sum_{p \in \widetilde{P}} u_{v p} \leq 1, \quad \forall v \in V, \\
& \sum_{i \in I} \sum_{p \in \widetilde{P}} \delta_{i l} m_{i p t} \leq n_{l}^{b}, \quad \forall t \in T, l \in L, \\
& \sum_{p \in \widetilde{P}} q_{i p}+\gamma_{i} \geq 1, \quad \forall i \in I .
\end{aligned}
$$

5.1.2. Mathematical Expressions of Submodels. The submodel (denoted as SM) is as shown in equations (26)-(41). $\widetilde{P}$ represents the new feasible single-ship-scheduling plan (i.e., a new column) to be generated. $\pi_{v}^{(23)}, \pi_{l t}^{(24)}$, and $\pi_{i}^{(25)}$ represent the shadow price from equations (23)-(25) of the $\mathrm{MM}$, and the rest of the symbols are the same as before. Equation (26) is the objective function of the SM, which means whether the single-ship feasible plan has a further probability for improvement. If the value of equation (26) is negative, $\widetilde{P}$ needs to be further optimized. Equations (27)-(41) are the constraint conditions for the SM. They are the corresponding equations of equations (1)-(15). The difference is that the $\widetilde{P}$ is used to replace the $p$ in original equations, which means the main characterization object of the SM is $\widetilde{P}$.

ECSSM-SM:

$$
\begin{aligned}
\min & \sum_{v \in V}\left(t_{\widetilde{e p}}^{s}-t_{0 \widetilde{p}}^{s}\right) c_{v}^{r} s_{v \widetilde{p}}-\sum_{v \in V} \pi_{v}^{(23)} s_{v \widetilde{p}}-\sum_{l \in L, t \in T} \pi_{l t}^{(24)} b_{\tilde{i p t}}-\sum_{i \in I} \pi_{i}^{(25)} a_{\widetilde{i p}}, \\
\text { s.t. } & \sum_{j \in I} \widetilde{x}_{0 j \widetilde{p}}=1, \\
& \sum_{i \in I} \widetilde{x}_{\widetilde{i e p}}=1,
\end{aligned}
$$




$$
\begin{aligned}
& \sum_{j \in I} \tilde{x}_{i \tilde{p} \tilde{p}}=\sum_{j \in I} \tilde{x}_{j i \tilde{p}}, \quad \forall i \in I, \\
& a_{\tilde{i p}}=\sum_{j \in I} \tilde{x}_{i \tilde{p} \bar{p}}, \quad \forall i \in I, \\
& t_{\tilde{j} \bar{p}}^{s} \geq t_{i \widetilde{p}}^{s}+t_{i \tilde{p}}^{w 1}+t_{i}^{h 1}+t_{i}^{r 1}+t_{i \tilde{p}}^{w 2}+t_{i}^{h 2}+t_{i}^{r 2}+M\left(1-\tilde{x}_{i j \tilde{p}}\right), \quad \forall i, j \in I, \\
& t_{0 \widetilde{p}}^{s} \geq \sum_{v \in V} t_{v}^{0} \times s_{v \widetilde{p}} \\
& a_{i \tilde{p}} t_{i}^{\mathrm{ls}} \leq t_{\tilde{i p}}^{s}+t_{i \tilde{p}}^{w 1} \leq a_{i \tilde{p}} t_{i}^{\mathrm{le}}, \quad \forall i \in I \\
& a_{\tilde{i} \bar{p}} t_{i}^{d s}+\left(1-a_{\tilde{i p}}\right)\left(t_{i}^{r 1}+t_{i}^{h 1}\right) \leq t_{i \widetilde{p}}^{s}+t_{\tilde{i} \bar{p}}^{w 1}+t_{i}^{r 1}+t_{i}^{h 1}+t_{i \widetilde{p}}^{w 2} \leq a_{i \widetilde{p}} t_{i}^{d e}+\left(1-a_{\tilde{i} \bar{p}}\right)\left(t_{i}^{r 1}+t_{i}^{h 1}\right), \quad \forall i \in I, \\
& b_{i \widetilde{p} t} \leq a_{i \tilde{p}}, \quad \forall i \in I \\
& t \geq t_{\tilde{i p}}^{s}+t_{\tilde{i p}}^{w 1}+t_{i}^{r 1}+t_{i}^{h 1}+t_{i \tilde{p}}^{w 2}-M\left(1-b_{\tilde{i p p}}\right), \quad \forall i \in I, t \in T \\
& t \leq t_{\widetilde{i p}}^{s}+t_{\tilde{i p}}^{w 1}+t_{i}^{r 1}+t_{i}^{h 1}+t_{i \bar{p}}^{w 2}+t_{i}^{h 2}+M\left(1-b_{i \tilde{p} t}\right), \quad \forall i \in I, t \in T, \\
& \sum_{t \in T} b_{\tilde{i p t}_{t}} \geq a_{i \bar{p}} t_{i}^{h 2}, \quad \forall i \in I, \\
& \sum_{v \in V} s_{v \widetilde{p}}=1 \\
& \sum_{v \in V} w_{v} \widetilde{a}_{i \widetilde{p} v} \geq D_{i} a_{i \widetilde{p}}, \quad \forall i \in I, \\
& \tilde{a}_{i \tilde{p} v}=a_{i \widetilde{p}} \cdot s_{v \widetilde{p}}, \quad \forall i \in I, v \in V .
\end{aligned}
$$

In the submodel, each waterway voyage $i$ is abstracted as a transportation node and the executing order of the voyage is regarded as the transportation between the node. Virtual nodes 0 and $\widetilde{e}$ are added additionally. Then, the subproblem in this section will be converted to an elemental shortest path problem with resource constraint (ESPPRC). Therefore, it can be solved using the common multidimensional labeling method. In this ESPPRC, the total cost of the whole route equals to the total costs of all nodes (water voyages) of the route.

\subsection{Design of Multidimensional Labeling.}

Multidimensional labeling requires labeling for each transportation node. The label $L_{i}$ used in this article contains a set of operational data for a $v$-type shuttle tanker from the port to the node $\operatorname{pos}\left(L_{i}^{v}\right)$. The labels in this chapter include three different types of information related to the problem attributes. (1) Voyage execution time $t\left(L_{i}^{v}\right)$ : it indicates the time required to reach the resident nodes of the tag following the waterway voyage sequence indicated by the tag. (2)
Voyage operation cost $c\left(L_{i}^{v}\right)$ : it represents the total operation cost of the ship when it reaches the resident node of the tag. (3) Resident node pos $\left(L_{i}^{v}\right)$ : it indicates the current node of waterway voyage $i$ where the ship extends. In particular, the $c\left(L_{i}^{v}\right)$ of initial label $L_{0}^{v}$ specification is 0 .

Based on such definition, the updates principle of the labels is as follows: (1) $t\left(L_{j}^{v}\right)=t\left(L_{i}^{v}\right)+t_{j}$; (2) $c\left(L_{j}^{v}\right)=$ $c\left(L_{i}^{v}\right)+c_{j}+\sum_{z \in Z, t \in T, k \in K} \pi_{z t\left(L_{i}^{v}\right)}^{(24)} b_{j k t\left(L_{i}^{v}\right)}+\pi_{j}^{(25)}$, where $t_{j}$ represents the operation time for the water voyage $j$. It should be noted that the decision variables of the original problem include the waiting time in the water voyage, so there will be multiple possibilities for the time and cost of completing the water voyage $i$ and the water voyage $j$ in sequence. In this chapter, the waiting time is measured in days, and the discrete processing is conducted for various situations, corresponding to the different transportation routes between the two nodes.

After defining the update rule, the domination rule is defined. For the same ship type $\mathrm{v}$, when the resident node of the labels $L_{1}^{v}$ and $L_{2}^{v}$ are the same FPSO, namely, 
$\operatorname{pos}\left(L_{1}^{v}\right)=\operatorname{pos}\left(L_{2}^{v}\right)$, if the following conditions are met, the label $L_{2}^{v}$ is dominated by the label $L_{1}^{v}$. The specific conditions are (1) less time consumption $t\left(L_{i}^{v}\right) \leq t\left(L_{j}^{v}\right)$; (2) less operation cost $c\left(L_{i}^{v}\right) \leq c\left(L_{j}^{v}\right)$.

\section{Numerical Experiments}

6.1. Experimental Design. At present, there are only two feasible algorithms for the ECSSP other than the CGSPA; one is the ESPA, and the other is a heuristic algorithm based on experience (denoted by PHA). Practice rule-based heuristic algorithm is the heuristic algorithm based on the operation rules derived from the practical transportation operation. The practical rules enable the PHA to effectively optimize the transportation task volume and maintain the advantage in enhancing computing efficiency by reducing computational time [37]. The heuristic algorithm is proved to be effective in solving the complex transportation network optimization problem involving multiple network nodes and multiple vehicles [37]. Thus, PHA is a suitable algorithm for the computing efficiency comparison.

In the first phase of our experiment, we demonstrate the advantages of the CGSPA by analyzing the performance of the CGSPA, ESPA, and PHA in terms of computational accuracy and efficiency. In the second stage of this experiment, we perform an optimization calculation for a real historical instance and analyze the results.

We use the transport demand and fleet data of a Chinese thermal power generation group in May and June 2015 (totaling 60 days) as data. Please refer to Table 2 for further details. The ports involved in the experiment are shown in Figure 4 . The loading port is the Tianjin Port (\#1). The unloading ports include the Shajiao North Port (\#2) and Shajiao South Port (\#3), Zhuhai Port (\#4), Jinwan Port (\#5), HuiLai Port (\#6), Shanwei Port (\#7), Shaoguan Port (\#8), Maoming Port (\#9), Xinsha Port (\#10), Haichang Port (\#11), Zhanjiang Port (\#12), Pinghai Port (\#13), Zhongyue Port (\#14), Yangjiang Port (\#15), and Luoding Port (\#16). We assume that 30 vessels can be rented, including three vessels of 20,000 tons, ten vessels of 20,000 to 60,000 tons, and 17 vessels of 60,000 to 90,000 tons. Please refer to Table 3 for further details regarding each ship (e.g., daily rent, available time, and detailed transportation capacity). In the first stage of the experiment, based on the abovementioned data, we randomly generate test data for the comparative calculation. In the second phase of the experiment, we directly use the abovementioned data for the optimization calculation.

6.2. Algorithm Efficiency. The calculation process of the ESPA is relatively simple. First, we obtain the set $P$ by enumeration, and then, we use Gurobi to solve the ECSSM model. In theory, the ESPA algorithm can solve the ECSSP accurately and is an ideal reference to evaluate the accuracy of the CGSPA. The calculation process of the PHA is relatively complex. This algorithm is the primary method used by power generation companies to solve the ECSSP. A summary of the PHA calculations is provided in Table 4, where Step 2.1 is the heart of the algorithm. Step 2.1 is used to estimate whether the ship $v^{\prime}$ can complete the task $i_{k}$ on time. For details, please refer to Table 5.

To compare the performance of the CGSPA, ESPA, and PHA, we generate 15 sets of test data based on the data given in Section 6.1. For convenience, we characterize these sets by the number of unloading ports $(P)$, the number of vessels that can be rented $(S)$, the length of the planning period $(D)$, and the number of tasks $(T)$. For example, if a dataset has five unloading ports, four ships, a planning period of 30 days, and ten tasks, this set is named P5S4D30T10. We use $\mathrm{C}++$ to program all the algorithms and use a PC which has an Intel I5-6500 CPU and 16 GB DDR4-2138 memory to run them. The integer program solver used by the CGSPA and ESPA is Gurobi 7.5.

Table 6 shows the calculation results and efficiency comparison of the three algorithms for each test. CDPT represents the total computation time of the CGSPA for solving the submodel, CGUT represents the total computation time of the algorithm calling Gurobi to solve the main model, and CGT represents the computation time of the entire calculations. ENT represents the time consumed by the ESPA to enumerate set $P$, EGUT represents the total time that the ESPA spends using Gurobi to solve the ECSSM, and EGT represents the total time that the ESPA takes to complete the calculations. \%CGSPA-ESPA and \% CGSPA-PHA present the gaps corresponding to the relative difference between the solution values of the CGSPA and ESPA and between the CGSPA and PHA, respectively. OM represents that the relevant calculation is aborted because the memory capacity of the computer is exceeded.

As shown in Table 6, the CGSPA is far superior to the ESPA in terms of computational efficiency. For example, in the small-sized example P4S7T10D30, the CGSPA obtained the optimal solution in $54.71 \mathrm{~s}$, whereas the ESPA took $5.02 \mathrm{~s}$. In the mid-size example P11S17T30D30, because of the size of set $\mathrm{P}$, the ESPA did not obtain an optimization result in an acceptable time $(3 \mathrm{~h})$, whereas the CGSPA completed the calculation in only $176.1 \mathrm{~s}$. In terms of accuracy, the CGSPA is far superior to PHA. For example, in the mid-sized example P9S13T20D40, the result of the CGSPA was $17.6 \%$ more accurate than the PHA result, whereas in the larger example P11S17T30D40, the CGSPA's result was 19.2\% more accurate than the PHA result. The abovementioned results illustrate that compared with the existing algorithms, the CGSPA has notable advantages in terms of computation time and calculation accuracy.

In addition, to test the robustness of the CGSPA, we perform multiple calculations by adjusting the rentable ship set. The results are shown in Table 7, where NUM of $\mathrm{P}^{\prime}$ represents the total number of $\mathrm{P}^{\prime}$ (the number of the columns) created by the CGSPA during the calculation. The number of rentable vessels is not positively related to the total time spent by the CGSPA. For example, P6S9T20D40 (7 ships) has a shorter computation time than P6S7T15D40 (9 ships). Further analysis indicates that the efficiency of the submodel solution and the total amount of $\mathrm{P}^{\prime}$ generated are the key factors determining the efficiency of the CGSPA. The results shown in Table 7 illustrate that the CGSPA has better robustness and can still solve the problem after specific parameters are changed. 
TABLE 2: The transport demand and fleet data of a Chinese thermal power generation group from May to June 2015.

\begin{tabular}{|c|c|c|c|c|c|}
\hline Id & Ship name & Earliest available time (days) & Earliest release time (days) & Dead weight (tons) & Daily rent (Yuan) \\
\hline 0 & Yuedian 1 & 9 & 40 & 6.9 & 2771 \\
\hline 1 & Yuedian 3 & 14 & 40 & 6.7 & 2713 \\
\hline 2 & Yuedian 4 & 0 & 40 & 7 & 2799 \\
\hline 3 & Yuedian 6 & 19 & 30 & 7.5 & 2943 \\
\hline 4 & Yuedian 7 & 10 & 40 & 7.5 & 2943 \\
\hline 5 & Yuedian 51 & 6 & 40 & 5.7 & 2426 \\
\hline 6 & Yuedian 54 & 17 & 40 & 5.7 & 2426 \\
\hline 7 & Yuedian 56 & 25 & 40 & 5.8 & 2454 \\
\hline 8 & Yuedian 57 & 15 & 30 & 5.8 & 2454 \\
\hline 9 & Yuedian 59 & 25 & 40 & 5.8 & 2454 \\
\hline 10 & Yuedian 103 & 34 & 50 & 8.7 & 3288 \\
\hline 11 & New Guangzhou & 1 & 30 & 6.5 & 2656 \\
\hline 12 & New Jinghai & 3 & 30 & 6.9 & 2771 \\
\hline 13 & New Ningjiang & 5 & 40 & 4.7 & 2138 \\
\hline 14 & Yuqi Sea & 3 & 30 & 6.4 & 2627 \\
\hline 15 & Yulin Sea & 9 & 30 & 7.5 & 2943 \\
\hline 16 & Guangzhu & 7 & 40 & 8.8 & 3317 \\
\hline 17 & Guangyue & 10 & 40 & 6.9 & 2771 \\
\hline 18 & Guangqian & 16 & 30 & 7.5 & 2943 \\
\hline 19 & Taihang 6 & 11 & 40 & 6.7 & 2713 \\
\hline 20 & Yuedian 52 & 38 & 0 & 5.7 & 2426 \\
\hline 21 & Yuedian 53 & 35 & 0 & 5.7 & 2426 \\
\hline 22 & Yuedian 58 & 21 & 0 & 5.6 & 2397 \\
\hline 23 & Yuedian 101 & 3 & 0 & 8.6 & 3259 \\
\hline 24 & Yuedian 102 & 17 & 0 & 8.6 & 3259 \\
\hline 25 & New Dajiang & 25 & 0 & 4.2 & 1995 \\
\hline 26 & Guanzhong & 48 & 0 & 6.6 & 2684 \\
\hline 27 & Enyao & 9 & 0 & 2.2 & 1391 \\
\hline 28 & Entend 1 & 14 & 0 & 2 & 1333 \\
\hline 29 & Entend 2 & 44 & 0 & 2 & 1305 \\
\hline
\end{tabular}

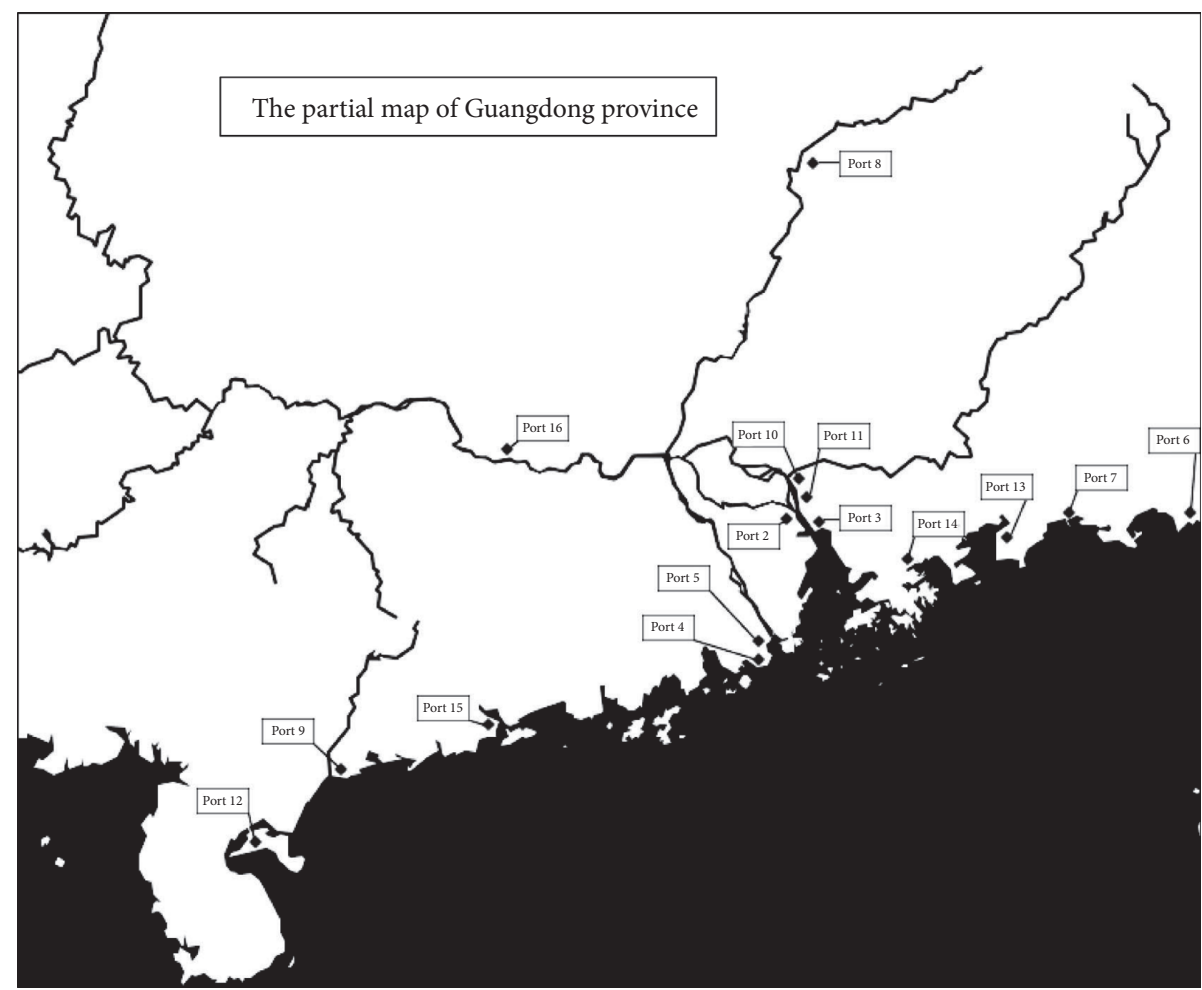

FIGURE 4: Geographical distribution of unloading ports. 
TABLE 3: The operational details of unloading ports.

\begin{tabular}{|c|c|c|c|c|c|c|}
\hline Id & Plant name & Min stock (tons) & Max stock (tons) & Consume rate (tons/day) & Current stock (tons) & Unload speed (tons/day) \\
\hline 0 & Sha A & 5.88 & 25 & 0.84 & 15.03 & 1.7 \\
\hline 1 & Sha C & 9.24 & 60 & 1.32 & 21.55 & 1.7 \\
\hline 2 & Huangpu & 3.71 & 20 & 0.53 & 7.47 & 2.4 \\
\hline 3 & Zhuhai & 6.65 & 33 & 0.95 & 19.792 & 2 \\
\hline 4 & Jinwan & 3.71 & 40 & 0.53 & 9.45 & 2 \\
\hline 5 & Shanwei & 13.37 & 39 & 1.91 & 23.833 & 3 \\
\hline 6 & Huilai & 6.51 & 50 & 0.93 & 40.2 & 3 \\
\hline 7 & Maoming & 2.24 & 15 & 0.32 & 9.655 & 1.5 \\
\hline 8 & Zhanjiang & 4.83 & 43 & 0.69 & 28.2 & 2 \\
\hline 9 & Yunhe & 4.62 & 29 & 0.66 & 10.49 & 2 \\
\hline 10 & Pinghai & 9.87 & 36 & 1.41 & 26.636 & 2 \\
\hline 11 & Zhongyue & 6.23 & 32 & 0.89 & 19.89 & 2 \\
\hline 12 & Shaoguan & 3.22 & 26 & 0.46 & 20.72 & 2.4 \\
\hline 13 & Yunfu & 1.89 & 26 & 0.27 & 16.08 & 2 \\
\hline 14 & Luoding & 1.54 & 15 & 0.22 & 2.86 & 2.2 \\
\hline
\end{tabular}

TABLE 4: A summary of the PHA calculation process.

PHA calculation process

Step 0: according to the lower bound of the unloading time window, sort the water voyages and obtain an ordered set $\widetilde{I}=\left\{i_{k}\right\}$, where $i_{k} \in I$, $k$ represents the number of the water voyage in $\widetilde{I}$, and for any $k, t d_{i_{k}}^{e} \leq t d_{i_{k}}^{e}$

Step 1: select the ship $v^{\prime}$ with the highest shipping capacity among the currently available ship set $V$ and obtain the currently available time point $t^{\prime}$ of the ship

Step 2: if $\widetilde{I} \neq \phi$ and $V \neq \phi$, then let $k=1$; else, go to step 3

Step 2.1: if the transportation volume of the task $i_{k}$ is no less than $60 \%$ of the capacity of $v^{\prime}$, the ship $v^{\prime}$ may complete the task as required (see Table 5); then, delete $i_{k}$ in $\widetilde{I}$, update the ship available time point $t^{\prime}$, and record that ship $v^{\prime}$ performs task $i_{k}$; else, let $k=k+1$

Step 2.2: if $k>|\widetilde{I}|$, or $t^{\prime}>|T|$, then remove $v^{\prime}$ from ship set $V$ and return step 2.1

Step 3: the calculation is completed

TABle 5: Procedure for determining whether vessel $v$ can process mission $i$ at time $t$.

Step 1: if the transportation loading of $i_{k}$ is larger than the ship capacity of vessel type $v$, then go to step false

Step 2: if $t \leq t_{i_{k}}^{\text {ls }}$, then $t_{i_{k}}^{w l}=t_{i_{k}}^{\text {ls }}-t, t=t_{i_{k}}^{\text {ls }}$ (calculating the waiting time at the loading port)

Step 3: if $t>t_{i_{k}}^{\text {le }}$, then go to step false

Step 4: if $t+t_{i_{k}}^{l}+t_{i_{k}}^{r 1}>t_{i_{k}}^{\text {ue }}$, then go to step false

Step 5: if $\left\{t^{\prime} \mid \sum_{t^{\prime \prime}=t^{\prime}}^{t^{\prime \prime}=t^{\prime}+t_{i_{k}}^{u}} b_{g_{k} t^{\prime \prime}}=0, t^{\prime} \leq t_{i_{k}}^{\mathrm{ue}}, t^{\prime} \geq t+t_{i_{k}}^{l}+t_{i_{k}}^{r 1}\right\}=\varnothing$, then go to step false

Step true: take $t^{\prime}=\min _{t^{\prime}}\left\{\sum_{t^{\prime \prime}=t^{\prime}}^{t^{\prime \prime} t^{\prime} t_{i_{k}}^{u}} b_{g_{k} t^{\prime \prime}}=0, t^{\prime} \leq t_{i_{k}}^{\mathrm{ue}}, t^{\prime} \geq t+t_{i_{k}}^{l}+t_{i_{k}}^{r 1}\right\}$ as the time of unloading

$t_{i_{k}}^{w u}=t^{\prime}-\left(t+t_{i_{k}}^{l}+t_{i_{k}}^{r 1}\right)$

For all $t^{\prime \prime} \in\left[t^{\prime}, t^{\prime}+t_{i_{k}}^{u}\right]$, execute $b_{g_{k}} t^{\prime \prime}=1$

$t=t^{\prime}+t_{i_{k}}^{r 2}$

Return true

Step false: $t=t-t_{i_{k}}^{w l}$, return false

(Return value: true, possible; false, and impossible)

6.3. Scenario Analysis. In the second phase of the experiment, we use the model and algorithm proposed in this paper to solve a real historical instance and compare the optimal solution with the actual electric coal transportation plan used by power generation enterprises. This issue considers all the rentable vessels given in Table 2, all the tasks given in Table 3, and all the ports given are in Section 6.1 with a 70-day planning horizon. The relevant rental fee of August and September in 2016 is set as the average relevant ship rental rate. The railway rates are taken from the China
Railway Corporation announced at the same time as the tariffs.

Comparisons of the key parameters of the electric coal transportation optimization plan and the actual transportation plan are shown in Table 8 and Figures 4-6, where OPR represents the optimized plan, RPR represents the actual transportation plan, NUM represents the number of vessels used, GRT represents the total renting duration of the vessels in days, GWT represents the total waiting time of the vessels in days, RTU represents the ratio of GRT to GWT, 
TABLE 6: CGSPA performance analysis.

\begin{tabular}{|c|c|c|c|c|c|c|c|c|c|}
\hline \multirow{2}{*}{ Test classes } & \multicolumn{3}{|c|}{ CGSPA } & \multicolumn{3}{|c|}{ ESPA } & \multirow{2}{*}{$\begin{array}{c}\text { PHA } \\
\text { PGT(s) }\end{array}$} & \multirow{2}{*}{$\%$ CGSPA-ESPA } & \multirow{2}{*}{ \% CGSPA-PHA } \\
\hline & CDPT(s) & CGUT(s) & CGT(s) & ENT(s) & EGUT(s) & EGT(s) & & & \\
\hline P2S2T4D20 & 0.042 & 0.007 & 0.05 & 0.09 & 0.53 & 0.62 & 0.10 & 0 & -2.5 \\
\hline P2S3T6D20 & 0.126 & 0.011 & 0.14 & 0.70 & 3.26 & 3.96 & 0.13 & 0 & -4.3 \\
\hline P4S6T10D20 & 0.224 & 0.025 & 0.25 & 1.12 & 7.78 & 8.90 & 0.19 & 0 & -4.0 \\
\hline P8S9T15D30 & 3.78 & 2.71 & 6.49 & 38.31 & OM & - & 0.27 & - & -11.2 \\
\hline P9S11T20D30 & 35.43 & 19.25 & 54.69 & 1437 & $\mathrm{OM}$ & - & 0.44 & - & -15.0 \\
\hline P11S13T25D30 & 128.8 & 27.9 & 156.7 & 1839 & $\mathrm{OM}$ & - & 1.09 & - & -16.8 \\
\hline P2S3T7D40 & 0.031 & 0.007 & 0.04 & 0.78 & 2.34 & 3.12 & 0.13 & 0 & -5.2 \\
\hline P3S6T10D40 & 1.68 & 0.143 & 1.82 & 3.07 & 12.32 & 15.39 & 0.20 & 0 & -6.9 \\
\hline P6S9T15D40 & 3.31 & 1.82 & 5.13 & 45.73 & $\mathrm{OM}$ & - & 0.30 & - & -15.3 \\
\hline P6S11T20D40 & 49.83 & 21.51 & 71.34 & 1643 & $\mathrm{OM}$ & - & 0.42 & - & -15.6 \\
\hline P9S13T25D40 & 61.97 & 26.16 & 88.13 & - & - & - & 0.54 & - & -16.1 \\
\hline P11S17T35D40 & 209.7 & 41.9 & 251.6 & - & - & - & 1.45 & - & -18.9 \\
\hline
\end{tabular}

TABLE 7: CGSPA reliability analysis.

\begin{tabular}{lcccc}
\hline Test classes & CDPT(s) & NUM of P' $(\mathrm{s})$ & CGUT(s) & CGT(s) \\
\hline P6S6T15D45 & 2.08 & 974 & 0.783 & 2.30 \\
P6S7T15D45 & 8.48 & 5035 & 0.709 & 8.72 \\
P6S8T20D45 & 6.25 & 4192 & 0.790 & 7.33 \\
P6S9T20D45 & 4.89 & 1647 & 0.97 & 6.19 \\
P6S20T20D45 & 10.41 & 1952 & 1.02 & 11.58 \\
\hline
\end{tabular}

TABLE 8: Key feature comparison between the optimized and actual plans.

\begin{tabular}{lcccccccccccccc}
\hline $\begin{array}{l}\text { Ship } \\
\text { type }\end{array}$ & $\begin{array}{c}\text { Dead } \\
\text { Weight(t) }\end{array}$ & NUM & $\begin{array}{c}\text { GRT } \\
\text { (days) }\end{array}$ & $\begin{array}{c}\text { GWT } \\
\text { (days) }\end{array}$ & $\begin{array}{c}\text { RTW } \\
\text { (days) }\end{array}$ & $\begin{array}{c}\text { AW } \\
\text { (tons) }\end{array}$ & RW & NUM & $\begin{array}{c}\text { GRT } \\
\text { (days) }\end{array}$ & $\begin{array}{c}\text { GWT } \\
\text { (days) }\end{array}$ & $\begin{array}{c}\text { RTW } \\
\text { (days) }\end{array}$ & $\begin{array}{c}\text { AW } \\
\text { (tons) }\end{array}$ & $\begin{array}{c}\text { RW } \\
\text { OPR-RPR }\end{array}$ \\
\hline Small & $<2 \mathrm{w}$ & 1 & 64 & 19 & 0.30 & 1.75 & 0.92 & 2 & 82 & 24 & 0.29 & 1.86 & 0.93 & \\
Medium & $2 \mathrm{w}-6 \mathrm{w}$ & 10 & 324 & 1 & 0.01 & 5.28 & 0.95 & 10 & 387 & 60 & 0.16 & 5.29 & 0.97 & $-22.60 \%$ \\
Large & $6 \mathrm{w}-9 \mathrm{w}$ & 14 & 605 & 3 & 0.01 & 6.96 & 0.96 & 17 & 814 & 173 & 0.21 & 6.94 & 0.96 \\
\hline
\end{tabular}

AW represents the average volume of transportation tasks undertaken by the vessels of the relevant type, RW represents the average utilization rate of the relevant vessels (i.e., the average ratio of the volume of completed traffic to the capacity of the relevant vessels), and \% OPR-RPR represents the relative standard deviation of the optimized plan and actual plan in total transportation costs. As shown in Table 6, the performance of the optimized plan in terms of capacity allocation is highly similar to that of the actual plan. Both use all the available ships and reach a high level of utilization (both exceeding 90\%). There was not a significant waste of capacity in either plan. However, the optimization plan is significantly better than the actual plan in terms of the time of use of the ships, with the effect being particularly evident for large electric coal transportation ships. Specifically, in the practical plan, the waiting time for large ships in the port accounts for more than $21 \%$ of the total renting duration, compared with only $0.01 \%$ in the optimized plan.

To further analyze the advantages of the optimized plan in reducing the waiting time of the vessels, Figure 5 compares the number of waiting ships on each observation point (day) between the optimized plan and the actual plan. The waiting time of ships during the planning period is

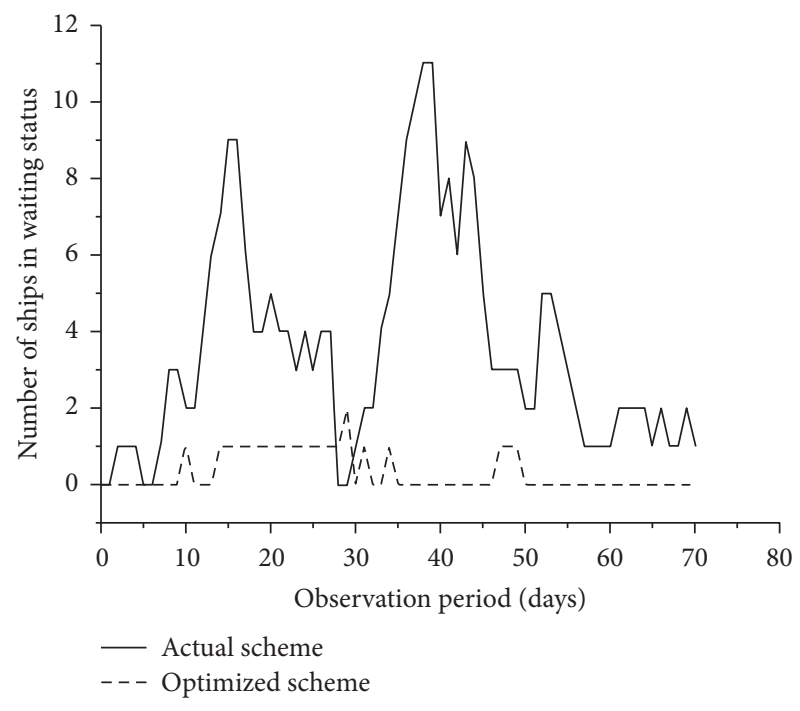

Figure 5: Comparative analysis of ships in waiting status.

significantly reduced in the optimized plan, with a daily average number of waiting ships of only 0.30 compared to 2.98 in the actual plan. The abovementioned analysis 


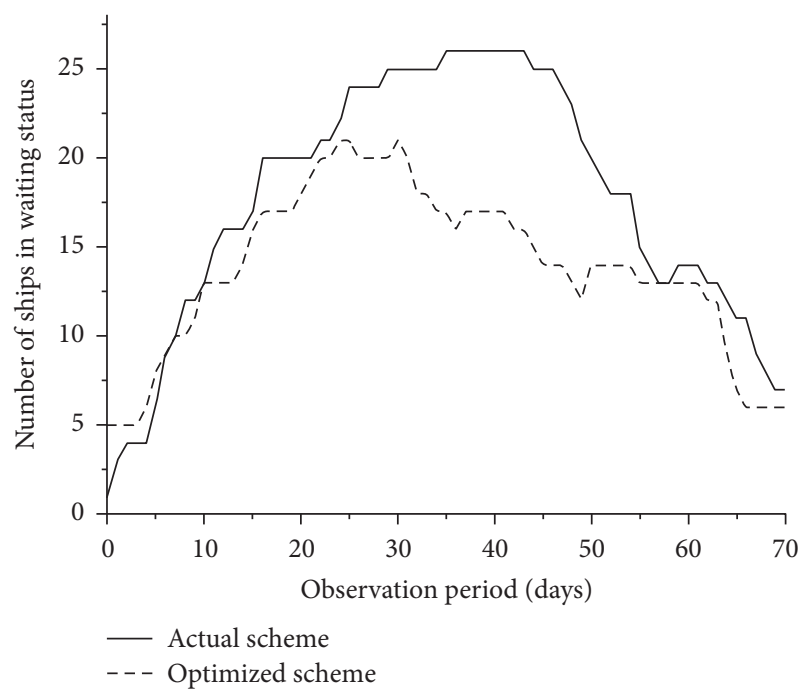

FIgURE 6: Comparative analysis of ships in waiting status.

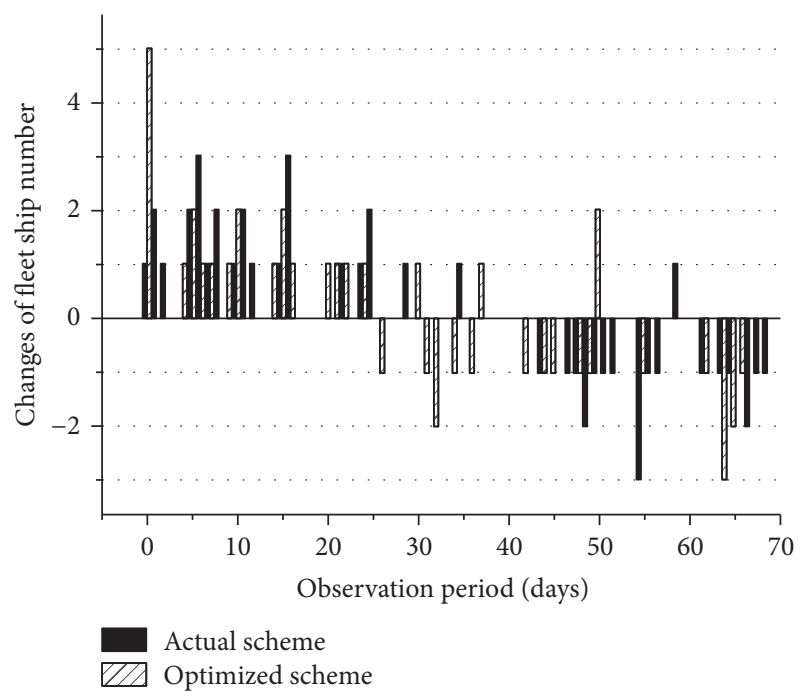

FIgURE 7: Comparative analysis of ships in waiting status.

illustrates that the optimized plan can effectively reduce the waiting time of the vessels at the unloading port while ensuring that the transportation tasks are completed as required, thus reducing the fleet operation and rental costs.

Figures 6 and 7 compare the differences between the optimized and actual plans in terms of fleet size, the time point to start renting a ship, and the time point to stop renting it. As shown in the figure, during phase A of the observation period (from day 0 to day 25), the overall size of the fleet used by both programs was controlled at a scale of 20-25 ships. The options for the two plans at the point of chartering are also similar. However, significant differences were observed during phase B of the observation period (day 25 to day 70). Due to the rationalization of the transportation assignment by the optimized plan, many vessels were allowed to be released on day 25 , whereas in the actual plan, releasing was not started until day 45 , when a large number of vessels were suspended. As a result, the average

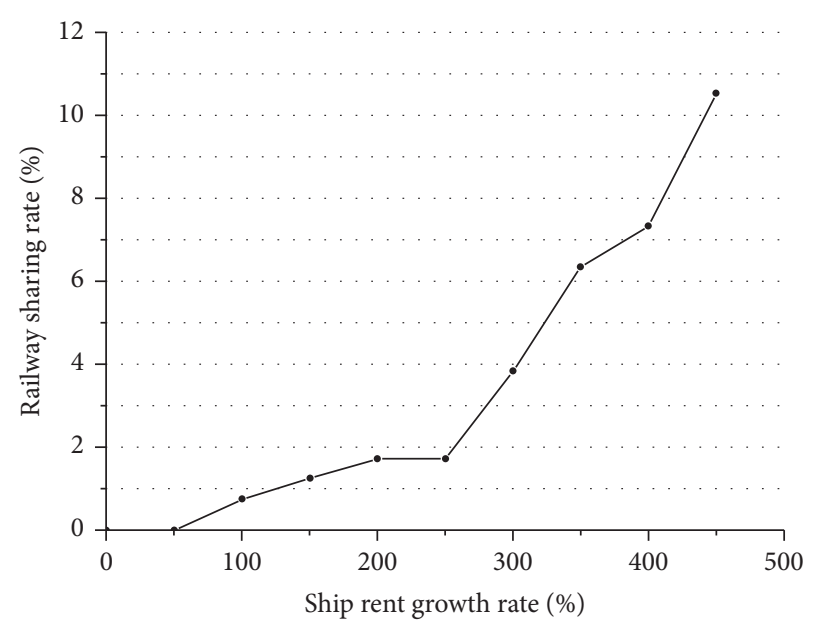

FIgURE 8: Relationship between ship rent growth and the railway freight sharing rate.

fleet size of the optimized plan in phase B was only 14.30 , compared to that of 19.65 in the actual plan. The smaller average fleet size combined with the lesser average vessel chartering time makes the optimized plan far superior to the actual plan in terms of electric coal transportation costs, with an approximate $22.60 \%$ reduction (\% OPR-RPR).

Neither the actual plan nor the optimized plan has applied rail transportation. In other words, water transportation is highly competitive in the actual cases covered in this paper. To determine the advantages of the competitiveness of water transportation, we use the model and algorithm proposed in this paper to study the impact of the floating rent of vessels on the competitiveness of water transportation. The results of the analysis are shown in Figure 8. Railway transportation begins to be employed when the daily rent increases by $50 \%$. The railway transportation share rate increases to $3.82 \%$ and $10.52 \%$ when the daily rent increases by $300 \%$ and $450 \%$, respectively. This result illustrates that, in the cases discussed in this experiment, the water transportation system is highly competitive and will not fundamentally change the condition that the electric coal transportation is dominated by water transportation even though the rents of ships have risen substantially.

\section{Conclusions}

In this paper, a new mathematic model for the ECSSP is developed with the consideration of the synergetic transportation of sea and rail, the time-window constraints of transportation tasks, and the congestion in the port. The model can be used to optimize fleet scheduling planning while considering the multiple transportation plan constraints. A precise algorithm is designed based on the architecture of the branch-and-price algorithm to effectively solve relatively large-scale optimization. The reliability of the model and algorithm is demonstrated through algorithm analysis and a practical case in the southern coastal areas of China. Results indicate that the proposed model and algorithm can effectively solve the ECSSP for the increasing 
transformation need in the coastal areas of Southern China. The total transportation cost is significantly reduced by reducing the total waiting time and the active vessels throughout the transportation task.

There are still issues that need further study. For example, in the transportation process, we assume that the transport system adopts the pattern of a single-vessel, singlemission, single-voyage system. Although this mode of transportation is a convention for the transportation of coal in China, it may lead to wasted shipping capacity in many cases. Therefore, how to optimize electric coal transportation under the condition of allowing multiple ships to participate in a set of voyage tasks is an interesting and challenging issue. Meanwhile, the ship's speed is assumed to be fixed, whereas a ship can adjust the speed in practice. Further studies should investigate the transportation of coal considering the variable speed.

\section{Data Availability}

The transport demand and fleet data used to support the findings of this study are included within the article.

\section{Conflicts of Interest}

The authors declare no conflicts of interest.

\section{Acknowledgments}

This work was supported by the Fundamental Research Funds for the Central Universities (No. 3132020227); the Department of Science and Technology of Liaoning Province (No. 2020JH2/10100042).

\section{References}

[1] Z. Tan, K. Chen, L. Ju, P. Liu, and C. Zhang, "Issues and solutions of China's generation resource utilization based on sustainable development," Journal of Modern Power Systems and Clean Energy, vol. 4, no. 2, pp. 147-160, 2016.

[2] J. Wang, R. Feng, and N. Meng, "Analysis on supply capability in seaborne-coal supply logistics system," in Proceedings of the 2008 IEEE International Conference on Service Operations and Logistics, and Informatics, pp. 3047-3051, Washington, DC, USA, December 2008.

[3] J. Chen, L. Jing, and J. Liang, "Design and implementation of coastal thermal coal transportation management and decision support system," Coal Technology, vol. 21, 2011.

[4] C. Wang and C. Ducruet, "Transport corridors and regional balance in China: the case of coal trade and logistics," Journal of Transport Geography, vol. 40, pp. 3-16, 2014.

[5] Q. Zeng and Z. Yang, "Model integrating fleet design and ship routing problems for coal shipping," in Proceedings of International Conference on Computational Science, pp. 10001003, Pune, India, August 2019.

[6] B.-H. Lin, H.-S. Lee, and C.-C. Chung, "The construction and implication of group scale efficiency evaluation model for bulk shipping corporations," Mathematics, vol. 8, no. 5, p. 702, 2020.

[7] I. Cera, Coal Rush: The Future of China's Coal Markets, IHS CERA, Cambridge, MA, USA, 2013.
[8] B. Rioux, P. Galkin, F. Murphy, and A. Pierru, "Economic impacts of debottlenecking congestion in the Chinese coal supply chain," Energy Economics, vol. 60, pp. 387-399, 2016.

[9] V. Reis, J. Fabian Meier, G. Pace, and R. Palacin, "Rail and multi-modal transport," Research in Transportation Economics, vol. 41, no. 1, pp. 17-30, 2013.

[10] A. Hemmati, L. M. Hvattum, M. Christiansen, and G. Laporte, "An iterative two-phase hybrid matheuristic for a multiproduct short sea inventory-routing problem," European Journal of Operational Research, vol. 252, no. 3, pp. 775-788, 2016.

[11] M. Christiansen, K. Fagerholt, B. Nygreen, and D. Ronen, "Ship routing and scheduling in the new millennium," European Journal of Operational Research, vol. 228, no. 3, pp. 467-483, 2013.

[12] D. Ronen, "Cargo ships routing and scheduling: survey of models and problems," European Journal of Operational Research, vol. 12, no. 2, pp. 119-126, 1983.

[13] M. Christiansen, K. Fagerholt, and D. Ronen, "Ship routing and scheduling: status and perspectives," Transportation Science, vol. 38, no. 1, pp. 1-18, 2004.

[14] D. Ronen, "Ship scheduling: the last decade," European Journal of Operational Research, vol. 71, no. 3, pp. 325-333, 1993.

[15] D. E. Lane, T. D. Heaver, and D. Uyeno, "Planning and scheduling for efficiency in liner shipping," Maritime Policy \& Management, vol. 14, no. 2, pp. 109-125, 1987.

[16] Q. Meng, S. Wang, H. Andersson, and K. Thun, "Containership routing and scheduling in liner shipping: overview and future research directions," Transportation Science, vol. 23, 2013.

[17] M. Christiansen and K. Fagerholt, "Robust ship scheduling with multiple time windows," Naval Research Logistics, vol. 49, no. 6, pp. 611-625, 2002.

[18] G. G. Brown, G. W. Graves, and D. Ronen, "Scheduling ocean transportation of crude oil," Management Science, vol. 33, no. 3, pp. 335-346, 1987.

[19] D. O. Bausch, G. G. Brown, and D. Ronen, "Scheduling shortterm marine transport of bulk products," Maritime Policy \& Management, vol. 25, no. 4, pp. 335-348, 1998.

[20] A. N. Perakis and W. M. Bremer, "An operational tanker scheduling optimization system: background, current practice and model formulation," Maritime Policy \& Management, vol. 19, no. 3, pp. 177-187, 1992.

[21] H. Jafari, "Measuring the performance of dry bulk cargo loading and unloading operation: latakia case study," Journal of Business and Management Sciences, vol. 1, pp. 77-82, 2013.

[22] N. S. F. A. Rahman, M. K. Othman, I. A. Sanusi, A. M. Arof, and A. Ismail, "Evaluation of delay factors on dry bulk cargo operation in Malaysia: a case study of kemaman port," The Asian Journal of Shipping and Logistics, vol. 35, no. 3, pp. 127-137, 2019.

[23] C. A. Kavirathna, T. Kawasaki, S. Hanaoka, and Y. M. Bandara, "Cooperation with a vessel transfer policy for coopetition among container terminals in a single port," Transport Policy, vol. 89, pp. 1-12, 2020.

[24] M. A. Dulebenets, "An adaptive island evolutionary algorithm for the berth scheduling problem," Memetic Computing, vol. 12, no. 1, pp. 51-72, 2019.

[25] H.-P. Hsu and C.-N. Wang, "Resources planning for container terminal in a maritime supply chain using multiple particle swarms optimization (MPSO)," Mathematics, vol. 8, no. 5, p. 764, 2020. 
[26] Y. Wang, Y. Yuan, X. Guan et al., "Collaborative two-echelon multicenter vehicle routing optimization based on statespace-time network representation," Journal of Cleaner Production, vol. 258, Article ID 120590, 2020.

[27] Y. Wang, S. Peng, X. Zhou, M. Mahmoudi, and L. Zhen, "Green logistics location-routing problem with eco-packages," Transportation Research Part E: Logistics and Transportation Review, vol. 143, Article ID 102118, 2020.

[28] G. Brønmo, M. Christiansen, K. Fagerholt, and B. Nygreen, "A multi-start local search heuristic for ship scheduling-a computational study," Computers \& Operations Research, vol. 34, no. 3, pp. 900-917, 2007.

[29] K. Kobayashi and M. Kubo, "Optimization of oil tanker schedules by decomposition, column generation, and timespace network techniques," Japan Journal of Industrial and Applied Mathematics, vol. 27, no. 1, pp. 161-173, 2010.

[30] K. Fagerholt, L. M. Hvattum, T. A. V. Johnsen, and J. E. Korsvik, "Routing and scheduling in project shipping," Annals of Operations Research, vol. 207, no. 1, pp. 67-81, 2013.

[31] J. E. Korsvik, K. Fagerholt, and G. Laporte, "A tabu search heuristic for ship routing and scheduling," Journal of the Operational Research Society, vol. 61, no. 4, pp. 594-603, 2010.

[32] I. Norstad, K. Fagerholt, and G. Laporte, "Tramp ship routing and scheduling with speed optimization," Transportation Research Part C: Emerging Technologies, vol. 19, no. 5, pp. 853-865, 2011.

[33] Y. Wang, X. Ma, Z. Li, Y. Liu, M. Xu, and Y. Wang, "Profit distribution in collaborative multiple centers vehicle routing problem," Journal of Cleaner Production, vol. 144, pp. 203219, 2017.

[34] E. Sopot and I. Gribkovskaia, "Routing of supply vessels to with deliveries and pickups of multiple commodities," Procedia Computer Science, vol. 31, pp. 910-917, 2014.

[35] M. Gansterer, M. Küçüktepe, and R. F. Hartl, "The multivehicle profitable pickup and delivery problem," OR Spectrum, vol. 39, no. 1, pp. 303-319, 2017.

[36] E. F. Cuesta, H. Andersson, K. Fagerholt, and G. Laporte, "Vessel routing with pickups and deliveries: an application to the supply of offshore oil platforms," Computers \& Operations Research, vol. 79, pp. 140-147, 2017.

[37] Y. Kim, K. Gotoh, and M. Toyosada, "Automatic two-dimensional layout using a rule-based heuristic algorithm," Journal of Marine Science and Technology, vol. 8, no. 1, pp. 37-46, 2003. 